\title{
Algorithm for the management of patients at low, high and very high risk of osteoporotic fractures
}

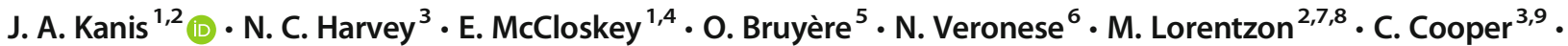 \\ R. Rizzoli ${ }^{10}$. G. Adib ${ }^{11} \cdot$ N. Al-Daghri ${ }^{12}$ - C. Campusano ${ }^{13} \cdot$ M. Chandran ${ }^{14} \cdot$ B. Dawson-Hughes ${ }^{15} \cdot$ K. Javaid $^{9}$. $^{9}$

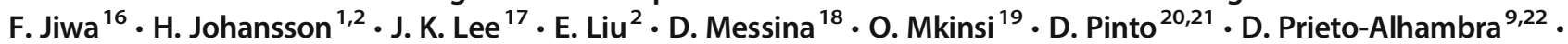 \\ K. Saag ${ }^{23} \cdot$ W. Xia ${ }^{24} \cdot$ L. Zakraoui ${ }^{25} \cdot$ J. -Y. Reginster ${ }^{12,26}$
}

Received: 26 June 2019 / Accepted: 18 September 2019 /Published online: 13 November 2019

(C) The Author(s) 2019, corrected publication 2020

\begin{abstract}
Summary Guidance is provided in an international setting on the assessment and specific treatment of postmenopausal women at low, high and very high risk of fragility fractures.

Introduction The International Osteoporosis Foundation and European Society for Clinical and Economic Aspects of Osteoporosis and Osteoarthritis published guidance for the diagnosis and management of osteoporosis in 2019. This manuscript seeks to apply this in an international setting, taking additional account of further categorisation of increased risk of fracture, which may inform choice of therapeutic approach.

Methods Clinical perspective and updated literature search.

Results The following areas are reviewed: categorisation of fracture risk and general pharmacological management of osteoporosis. Conclusions A platform is provided on which specific guidelines can be developed for national use to characterise fracture risk and direct interventions.
\end{abstract}

Keywords Anabolic agents · Fracture risk assessment · FRAX · Inhibitors of bone resorption · Treatment of osteoporosis

\section{Introduction}

In 2018, the International Osteoporosis Foundation (IOF) and the European Society for Clinical and Economic Evaluation of Osteoporosis and Osteoarthritis (ESCEO) updated guidelines for the diagnosis and management of postmenopausal osteoporosis, subsequently published in full in 2019 [1] and as executive summaries [2, 3]. Translation of this guideline into easy to use, practical algorithms is needed to facilitate the recognition and

Outcomes of an experts' consensus meeting jointly organised by the European Society for Clinical and Economic Aspects of Osteoporosis, Osteoarthritis and Musculoskeletal Diseases (ESCEO) and the International Osteoporosis Foundation (IOF)

\section{J. A. Kanis}

w.j.Pontefract@ shef.ac.uk

Extended author information available on the last page of the article treatment of women at increased risk of fracture. This translation could also enable the incorporation of several recent developments that significantly impact on strategies for the management of patients. The first is the widespread recognition that the risk of a subsequent osteoporotic fracture is particularly acute immediately after an index fracture and wanes progressively with time [4-9]. This very high fracture risk and the consequent further utility loss immediately after a subsequent fracture (often termed "imminent risk" because of the temporal association) suggests that preventive treatment given as soon as possible after fracture would avoid a higher number of new fractures and reduce the attendant morbidity, compared with treatment given later. This provides the rationale for very early intervention immediately after a sentinel fracture and necessitates treatment with agents that have the most rapid effect on fracture reduction. A further recent development is the demonstration of a more rapid and greater fracture risk reduction of anabolic compared with antiresorptive treatments [10-14], with the potential to revolutionise treatment strategies, particularly in individuals at very high fracture risk $[15,16]$. 
The scope of the present report is to review and update the assessment of osteoporosis, in particular the categorisation of risk to better target therapeutic interventions for the prevention of fragility fracture in postmenopausal women. The guideline is intended for all healthcare professionals involved in the management of osteoporosis. Where available, systematic reviews, meta-analyses and randomised controlled trials have been used to provide the evidence-base with the available literature updated using PubMed to identify systematic reviews and meta-analyses from January 2017 to December 2018, subsequent to the generation of the recent European Guidelines. The recommendations in this guidance have been endorsed by the Scientific Advisory Board of ESCEO and the Committee of Scientific Advisors and the Committee of National Societies of the IOF.

\section{Risk assessment}

The IOF and ESCEO recommend that risk of fracture should be expressed as an absolute risk, i.e. probability of fracture over a ten-year interval [1]. The absolute risk of fracture depends upon age and life expectancy as well as the current fracture risk. The period of 10 years was chosen to cover the likely length of treatment and the time over which benefits may continue or risks arise if treatment is stopped [17]. Algorithms that integrate the weight of clinical risk factors for fracture risk, with or without information on BMD, were developed in 2007 by the then WHO Collaborating Centre for Metabolic Bone Diseases at Sheffield. The resulting FRAX tool (www.shef.ac.uk/FRAX) computes the 10-year probability of hip fracture or a major osteoporotic fracture, the latter comprising a clinical spine, hip, forearm or humerus fracture. The tool has been externally validated in independent cohorts [18] and calibrated to the epidemiology of fracture and death in 67 countries covering more than $80 \%$ of the world population at risk [19].

\section{Intervention and assessment thresholds}

FRAX has been incorporated into more than 100 guidelines worldwide but the approach to intervention thresholds has varied widely $[19,20]$. For the purposes of this report, the guidance of the IOF and ESCEO [1] is used as an example and shown in Fig. 1.

In the European guidance, it is recommended that postmenopausal women with a prior fragility fracture should be treated without further assessment, although BMD measurement and incorporation into the FRAX calculation is sometimes appropriate, particularly in younger postmenopausal women. In women without a previous fragility fracture, the management strategy should be based on assessment of the ten-year probability of a major osteoporotic fracture (clinical spine, hip,
Ten year probability (\%)

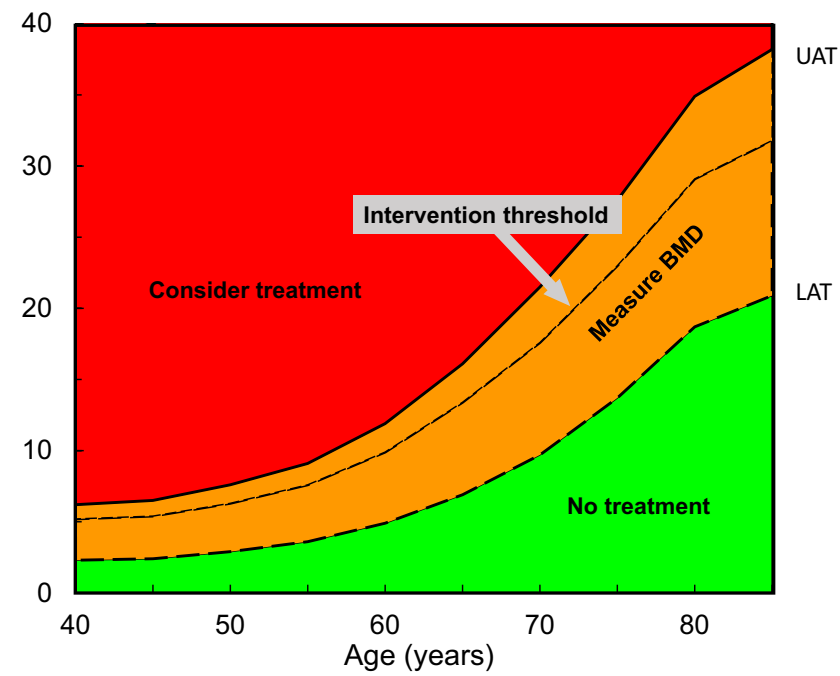

Fig. 1 Assessment guidelines based on the ten-year probability of a major osteoporotic fracture (\%). The dotted line denotes the intervention threshold. Where assessment is made in the absence of BMD, a BMD test is recommended for individuals where the probability assessment lies in the orange region i.e. between the lower assessment threshold (LAT) and the upper assessment threshold (UAT). The intervention threshold and BMD assessment thresholds used are those derived from [1] and reproduced in the Appendix, Table 5, with kind permission from Springer Science and Business Media

forearm or humerus). Women with probabilities below the lower assessment threshold can be considered at low risk. Women with probabilities above the upper assessment threshold can be considered for treatment. Women with probabilities between the upper and lower assessment threshold should be referred for BMD measurements and their fracture probability reassessed [1]. The age-dependent intervention threshold is set at a risk equivalent to that associated with a prior fracture in a woman of the same age with average BMI and, therefore, rises with age [21]. The same thresholds are used in men since the cost-effectiveness of interventions is broadly similar in men and women $[22,23]$.

Fig. 2 Infographic outlining of the characterisation of fracture risk by FRAX major osteoporotic fracture probability in postmenopausal women. Initial risk assessment uses FRAX with clinical risk factors alone. FRAX probability in the red zone indicates very high risk and that an initial course of anabolic treatment followed by antiresorptive therapy may be appropriate. FRAX probability in the green zone suggests low risk, with advice to be given on lifestyle, calcium and vitamin D nutrition and menopausal hormone treatment considered. FRAX probability in the intermediate (orange) zone should be followed by BMD assessment and recalculation of FRAX probability including femoral neck BMD. After recalculation, risk may be in the red zone (very high risk), orange zone (high risk, which suggests initial antiresorptive therapy) or green zone (low risk, either in the original green zone or in the original orange zone but below the intervention threshold). Note that patients with a prior fragility fracture are at least designated at high risk and possibly at very high risk dependent on the FRAX probability 

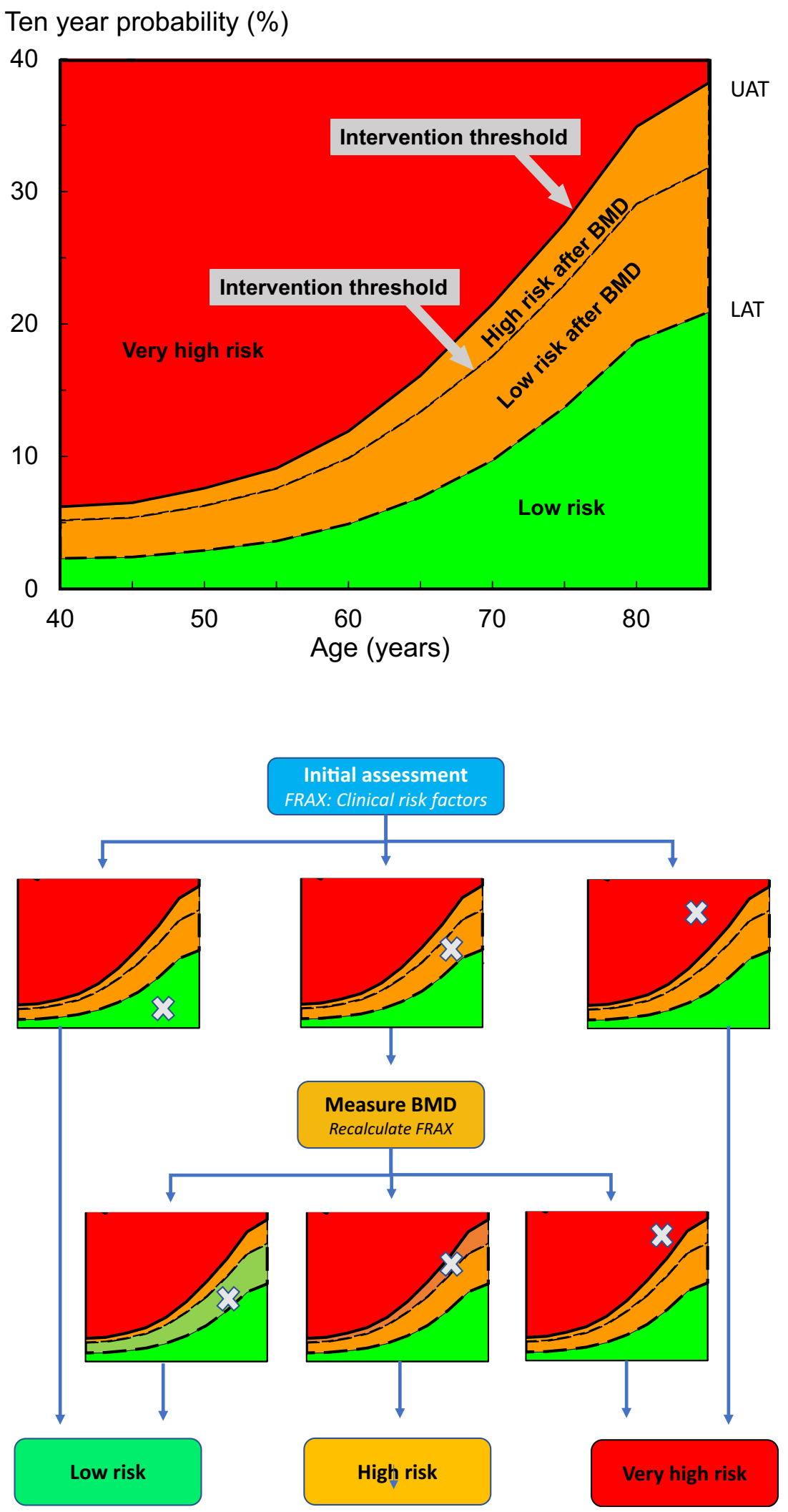

Some agencies have been reluctant to reimburse treatments on the basis of fracture probability, particularly at younger ages where the 10 -year probability of a major osteoporotic fracture is less than $10 \%$. In the UK, for example, the intervention threshold for women aged $50-54$ years is $8.18 \%$. At the same age, however, the remaining lifetime probability of a 
Fig. 3 Treatment pathways according to the categorisation of fracture risk. For treatment modalities (inhibitors of bone resorption, anabolic agents, etc.), see Appendix, Table 6
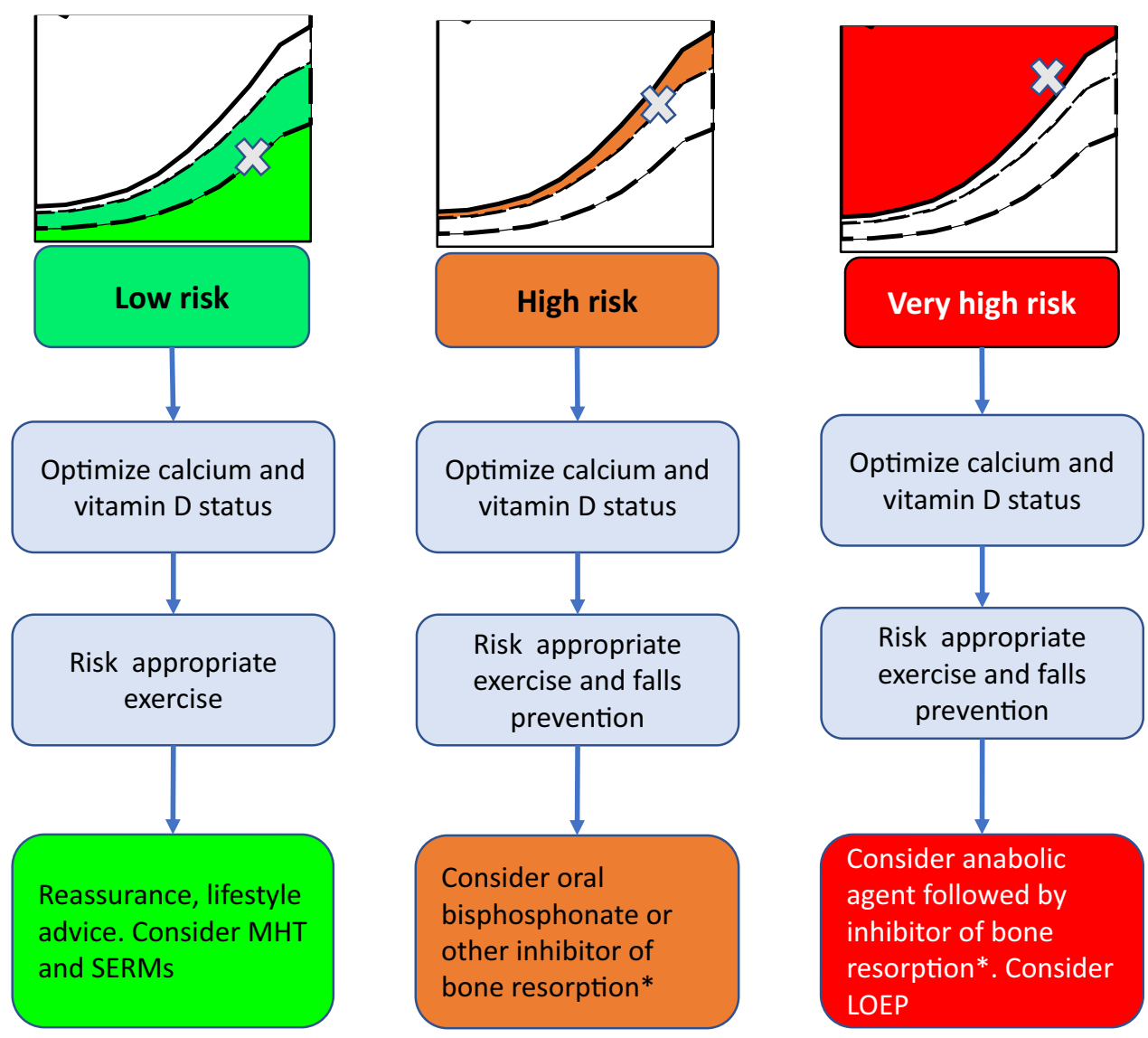

$\mathrm{MHT}$, menopausal hormone therapy;

SERM, selective estrogen receptor modulator;

LOEP, local osteo-enhancement procedure

* See Appendix, table A2
Fig 4 Proportion (\%) of postmenopausal women by age in a simulated normal population of 50633 women from the UK [51] characterised at low, high and very high risk. The high-risk category includes women with a prior fracture not characterised at very high risk. Numbers in the high and very high risk categories refer to the percentage so characterised at each age interval

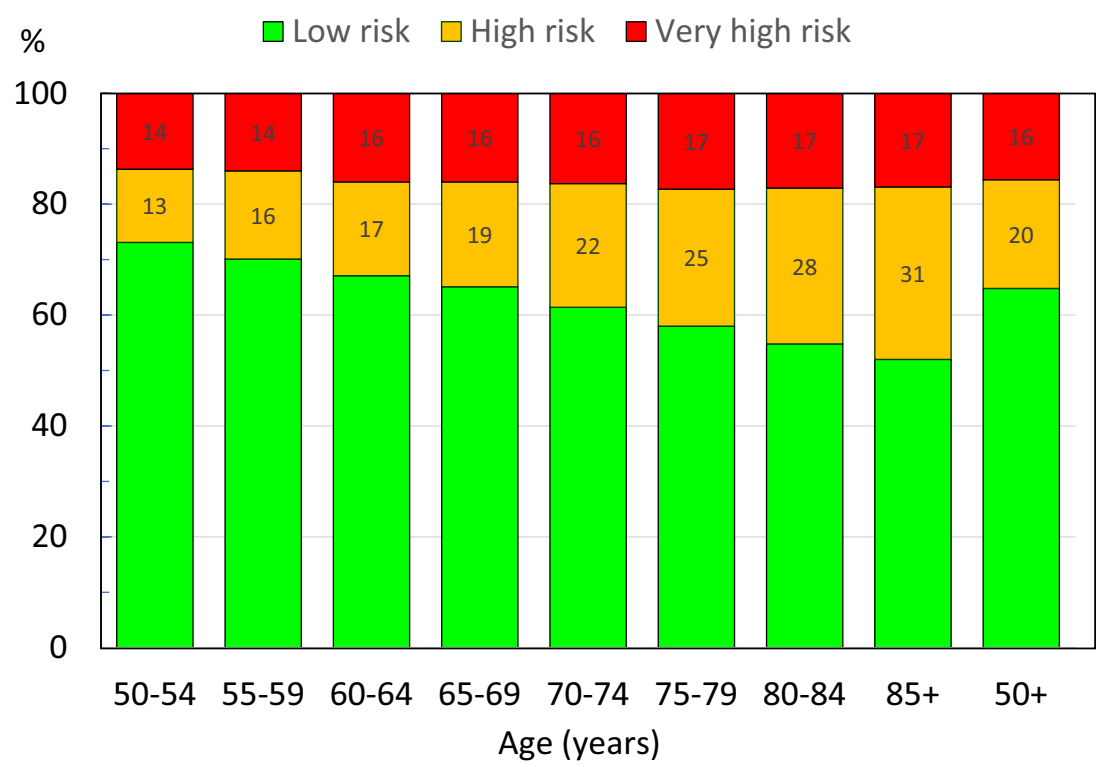


major fracture is high $(57 \%)$. Moreover, there are costeffective scenarios for treatment available at these levels of risk [1].

In addition to the 10-year probability of a major osteoporotic fracture, the European guidance also provides intervention thresholds that are based on the 10-year probability of hip fracture. Either or both thresholds can be used; indeed, the screening for prevention of fractures in older women (SCOOP) trial showed that a screening strategy decreased the incidence of hip fracture (but not other fractures), based on treatment targeted by hip fracture probability [24].

To enhance fracture risk assessment, relatively simple arithmetic adjustments have been developed, which can be applied to conventional FRAX estimates of probabilities of hip fracture and a major fracture to adjust the probability assessment with knowledge of

High, moderate and low exposure to glucocorticoids [25]

Concurrent data on lumbar spine BMD [26, 27]

Trabecular bone score of the lumbar spine [28-30]

Hip axis length [31]

Falls history [32]

Immigration status [33]

Type 2 diabetes [34, 35]

Chronic kidney disease [36]

Recency of fracture $[9,37]$

\section{Categorisation of risk}

The assessment strategy above permits the classification of risk. In addition to the categories of low and high risk espoused in the current IOF-ESCEO guideline, very high risk can be identified as outlined in Fig. 2. Very high risk is defined as a fracture probability that lies above the upper assessment threshold after a FRAX assessment, with or without the inclusion of BMD, i.e. where BMD testing is unavailable, the same probability threshold can be used. The numerical data for
Table 2 10-year probability of major osteoporotic fracture (MOF) for Icelandic women at different ages, categorised by (A) a clinical vertebral fracture within the previous 2 years and (B) a prior fracture of undetermined recency. The right-hand column provides the ratio by which to adjust FRAX probabilities by virtue of a recent clinical vertebral fracture. From [59], with kind permission from Springer Science and Business Media

\begin{tabular}{|c|c|c|c|}
\hline \multirow[b]{2}{*}{ Age } & \multicolumn{2}{|c|}{ 10-year probability of MOF } & \multirow[t]{2}{*}{ Ratio } \\
\hline & $\begin{array}{l}\text { (A) Recent } \\
\text { vertebral fracture }\end{array}$ & $\begin{array}{l}\text { (B) Prior fracture } \\
\text { in adult life }\end{array}$ & \\
\hline 50 & 29.0 & 11.7 & 2.47 \\
\hline 60 & 36.1 & 19.4 & 1.86 \\
\hline 70 & 41.9 & 27.6 & 1.52 \\
\hline 80 & 42.5 & 34.2 & 1.24 \\
\hline 90 & 34.7 & 33.3 & 1.04 \\
\hline
\end{tabular}

these thresholds are given in the Appendix (Table 5) based on the weighted average of 5 European countries (Germany, France, Italy, Spain and the UK) but will vary by country.

\section{Impact on treatment}

The rationale for the more refined characterisation of risk is to direct appropriate interventions. Thus, initial treatment recommendations for women at high risk might most usually start with an inhibitor of bone resorption. For example, the UK National Institute for Clinical Excellence (NICE) and the IOF/ESCEO guidelines recommend oral bisphosphonates [1, 38,39 ] but a very large range of pharmacological interventions are recommended worldwide (Appendix, Tables 6 and 7). In contrast, women at very high risk might be more suitably treated with an anabolic treatment followed thereafter by an inhibitor of bone resorption [40] (Fig. 3).

Non-pharmacological management should be considered for all patients but may be adapted according to the category
Table 1 Examples of risk assessment in women from the UK (BMI set to $25 \mathrm{~kg} / \mathrm{m}^{2}$ ). Risk factors include prior fracture (of uncertain recency), prior clinical vertebral fracture within the past two years, family history of hip fracture, exposure to glucocorticoids, exposure to higher than average doses of glucocorticoids and bone mineral density (BMD) T-score at the femoral neck

\begin{tabular}{|c|c|c|c|c|c|c|c|c|}
\hline Age (years) & Prior fracture & Recent spine fracture & Family history & $\mathrm{GC}$ & GC high dose & BMD (T-score) & 10 -year probability (\%) & Category of risk \\
\hline 70 & Yes & & & & & - & 20 & Low $^{1}$ \\
\hline 70 & & & Yes & & & - & 17 & Low \\
\hline 70 & Yes & & Yes & & & - & 30 & Very high \\
\hline 70 & & Yes & & & & - & 30 & Very high \\
\hline 60 & & & & Yes & & -1.5 & 10 & Low \\
\hline 60 & & & & Yes & & -2.0 & 13 & High \\
\hline 60 & & & & Yes & Yes & -2.0 & 15 & Very high \\
\hline
\end{tabular}

${ }^{1}$ Qualifies for treatment by virtue of a prior fracture 
Table 3 Unadjusted probabilities of a major fracture in women with a prior fragility fracture by age using the UK FRAX model together with the categories of risk and adjusted FRAX probabilities for women with a recent clinical vertebral fracture. BMI set at $24 \mathrm{~kg} / \mathrm{m}^{2}$

\begin{tabular}{llllll}
\hline & \multicolumn{3}{l}{ Prior fracture in adult life } & & \multicolumn{2}{l}{ Recent clinical vertebral fracture } \\
\cline { 2 - 3 } Age & Probability (\%) & Category of risk & & Probability (\%) & Category of risk \\
\hline 50 & 7.3 & High & & 18.0 & Very high \\
60 & 12.2 & High & & 22.7 & Very high \\
70 & 20.3 & High & & 30.9 & Very high \\
80 & 27.6 & Very high & & 34.2 & Very high \\
90 & 33.9 & Very high & & 35.3 & Very high \\
\hline
\end{tabular}

of fracture risk [41, 42]. For all patients, education on osteoporosis (e.g. knowledge of osteoporosis, medications, diet and exercise) and advice for daily weight-bearing physical activity are appropriate [43-45]. Where indicated, the addition of fall prevention measures, including supervised exercise and/or rehabilitation, has been shown to be useful in reducing falls [46, 47] but the effects on fracture risk remain uncertain [47]. Programmes should continue over a duration of at least 50 hours, be progressive in nature and include strength and balance training components [48-50].

The implications of the categorisation of risk on the use of anabolic regimens in this way are shown in Fig. 4 as applied to the age-specific NOGG guidance [21]. As would be expected, the proportion of women characterised at low risk decreased with age and, conversely, those at high risk increased with age. The proportion of women characterised at very high risk increased with age though the quantum of effect was modest. Overall, in women aged 50 years or more, $64.8 \%$ were categorised at low risk, $19.7 \%$ at high risk and $15.6 \%$ at very high risk. Numerical data by age are given in the Appendix (Table 6).

Table 4 The effect on hip fracture (number/1000 patient years) of an anabolic agent (AA) given for the first 18 months followed by an antiresorptive (AR) for a total of 10 years. The clinical scenario is a postmenopausal woman from the UK with a recent major osteoporotic fracture. The efficacy (RRR) of the anabolic agent is modelled at $70 \%$ and

\section{Examples of very high risk}

A prior fragility fracture provides informative examples of the categorisation of risk and recommendations for treatment which are illustrated for a woman age 70 years in Table 1. A prior fragility fracture of undetermined recency is associated with a 10 -year probability of a major osteoporotic fracture of $16 \%$. Whereas this probability is designated as low, treatment with an inhibitor of bone resorption is indicated by the IOF-ESCEO guidance and many other guidelines by virtue of the prior fracture [19]. A family history of hip fracture in the absence of any other risk factors provides a similar fracture probability is characterised at low risk and lifestyle advice recommended. The combination of a prior fragility fracture of uncertain recency and a family history of hip fracture is associated with a much higher risk than either risk factor alone or falls into the category of very high risk where an anabolic regimen might be recommended.

A further example of the interaction of risk factors on the categorisation of risk is provided in the context of exposure to glucocorticoids (see Table 1). A woman aged 60 years exposed to average doses of glucocorticoids and a femoral neck T-score of -

that of the antiresorptive at $40 \%$. The time course of a subsequent hip fracture is non-linear as given in [58]. The two right-hand columns show the effects of an antiresorptive followed by an anabolic agent for the last 18 months of a 10 -year treatment

\begin{tabular}{llllll}
\hline & Untreated & $\begin{array}{l}\text { AA/AR } \\
\text { RRR 70/40\% }\end{array}$ & Fractures saved & AR/AN & Fractures saved $^{\mathrm{b}}$ \\
& & RRR 40/70\% & \\
\hline Age & $\mathrm{N} / 1000$ & $\mathrm{~N} / 1000$ & $\mathrm{~N} / 1000$ & $\mathrm{~N} / 1000$ & $\mathrm{~N} / 1000$ \\
50 & 8.1 & 2.4 & 5.7 & 4.7 & 3.4 \\
55 & 12.8 & 3.8 & 9.0 & 7.5 & 5.3 \\
60 & 20.4 & 6.1 & 14.3 & 11.9 & 8.5 \\
65 & 31.3 & 9.4 & 21.9 & 18.3 & 13.0 \\
70 & 48.3 & 14.5 & 33.8 & 28.3 & 20.0 \\
75 & 73.6 & 22.1 & 71.5 & 43.1 & 30.5 \\
80 & 104.7 & 31.4 & 112.3 & 61.2 & 43.5 \\
85 & 160.4 & 48.1 & 126.6 & 93.8 & 66.6 \\
90 & 180.9 & 54.3 & 105.8 & 75.1 \\
\hline
\end{tabular}

${ }^{a}$ It is assumed that the effect of the anabolic agent is maintained with the subsequent antiresorptive agent

${ }^{\mathrm{b}}$ First fractures 
1.5 would be characterised as being at low risk in the absence of other clinical risk factors. A lower T-score of -2.0 would place her in the category of high risk. However, for high doses (> $7.5 \mathrm{mg}$ daily), probabilities should be upward-revised by about $15 \%[25,52]$ which would place the patient at very high risk.

There is now a substantial body of evidence that the risk of a subsequent osteoporotic fracture is particularly acute immediately after the index fracture and wanes progressively with time [4-8, 53-57]. Thus, the incidence of a second fracture in those who will sustain a further fracture is particularly high in the first 2 years after the index event [58]. In the case of hip fracture, $61 \%$ of subsequent fractures over a 10 -year time horizon will occur within the first 2 years. For forearm, spine and humerus fractures the recurrence within two years is 54 , 42 and 53\%, respectively. A recent population-based study demonstrated that the phenomenon of immediate risk was also age dependent [9]. For a woman at age 70 years, a prior clinical vertebral fracture within the past 2 years is associated with a 1.52-fold higher fracture probability than for a woman of the same age with a prior fragility fracture of uncertain recency [59] (Table 2). Thus, a recent clinical vertebral fracture uplifts the fracture probability from 16 to $24 \%$ and would place the woman in the category of very high risk (see Table 1).

Risk stratification with NOGG guidelines* BMI set at $25 \mathrm{~kg} / \mathrm{m}^{2}$

The ratios given in Table 2 can be used to adjust fracture probabilities derived from FRAX for recency of clinical vertebral fracture. Table 3 gives the current probabilities of a major fracture in women with a prior fragility fracture of uncertain recency using the UK FRAX model together with the adjusted probabilities for women with a clinical vertebral fracture within the past two years.

\section{Impact of sequential treatment on fracture}

In patients at very high risk of fracture, starting treatment with an anabolic agent seems most appropriate to promptly reduce the fracture risk [60-62]. Given that treatments with anabolic agents are limited to 12-24 months and that efficacy will wane once treatment is stopped, the real potential of the anabolic treatments is that their greater effect on BMD and fracture can be maintained with the inhibitors of bone turnover once anabolic treatment is stopped [11, 63, 64]. Take for example a hypothetical anabolic agent that reduced the risk of hip fracture by $70 \%$ (relative risk reduction, $\mathrm{RRR}=70 \%$ ). In this case, the anabolic agent, followed by an antiresorptive to maintain the effect for a total of 10 years, might be expected to save 33.8 hip fractures $/ 1000$ patient years in women age 70 years with a recent fragility fracture. In contrast, an antiresorptive $(\mathrm{RRR}=40 \%)$ followed by an anabolic regimen for the last 18 months of a 10 -year treatment would save only 20.0 hip fractures/1000 patient years. The difference illustrates the importance of the sequence. The assumptions used and data for other ages are given in Table 4.

\section{Conclusion}

The risk categorisation of individuals deemed to merit treatment into high and very high risk and aids the targeting of anabolic therapy followed by antiresorptive medications.

Acknowledgements We are grateful to the Scientific Advisory Board of ESCEO and the Committee of Scientific Advisors and the Committee of National Societies of the IOF for their review and endorsement of the recommendations in this guidance.

\section{Compliance with ethical standards}

Conflicts of interest NM Al-Daghri G Adib, C Campusano, M Chandran, F Jiwa, H Johansson, JK Lee, E Liu, D Pinto, N Veronese, W Xia, L Zakraoui have no conflicts of interest to declare.

$\mathrm{O}$ Bruyère received research grants from Biophytis, IBSA, MEDA, Servier and SMB and consulting or lecture fees from Amgen, Biophytis, IBSA, MEDA, Servier, SMB, TRB Chemedica and UCB.

C Cooper reports personal fees from Alliance for Better Bone Health, Amgen, Eli Lilly, GSK, Medtronic, Merck, Novartis, Pfizer, Roche, Servier, Takeda and UCB.

B. Dawson-Hughes has received grant support from Pfizer and DSM and consulting fees from TTY Biopharma Co, Ltd, Intrinsic Therapeutics and Agnovos.

NC Harvey has received consultancy/lecture fees/honoraria/grant funding from Alliance for Better Bone Health, Amgen, MSD, Eli Lilly, Radius Health, Servier, Shire, UCB, Consilient Healthcare and Internis Pharma.

MK Javaid has received honoraria, unrestricted research grants, travel and/or subsistence expenses from Amgen, Lilly UK, Internis, Consilient Health, Zebra Medical Vision, Kyowa Kirin Hakin and UCB.

JA Kanis reports grants from Amgen, Eli Lilly and Radius Health and consulting fees from Theramex. JAK is the architect of FRAX® but has no financial interest.

M Lorentzon has received lecture fees from Amgen, Lilly, Meda, Renapharma and UCB Pharma and consulting fees from Amgen, Radius Health, UCB Pharma, Renapharma and Consilient Health, all outside the presented work.

EV McCloskey has received consultancy/lecture fees/grant funding/ honoraria from ActiveSignal, AgNovos, Amgen, AstraZeneca, Consilient Healthcare, Fresenius Kabi, Gilead, GSK, Hologic, Internis, Lilly, Medtronic, Merck, Novartis, Pfizer, Radius Health, Redx Oncology, Roche, SanofiAventis, Servier, Synexus, Tethys, UCB, Viiv, Warner Chilcott, I3 Innovus and Unilever.

OD Messina has received honoraria from Amgen, Lilly, Novartis and Pfizer

O Minski received honorary fees for lectures, from Abbvie, Roche, Pfizer, Pierre Fabre, Janssen, Novartis and MSD.

D Prieto-Alhambra's research group has received research grants from Amgen, Servier and UCB; speaker fees from Amgen and UCB; educational grants from Johnson \& Johnson and consultancy fees from Amgen and UCB.

J-Y Reginster has received advisory board or consulting fees from IBSA-Genévrier, Pierre Fabre, Radius Health, TEVA and Mylan; lecture fees from Agnovos, IBSA-Genévrier, Mylan, CNIEL, Dairy Research Council (DRC) and Theramex and institutional grant support from IBSA-Genévrier, Mylan, CNIEL and Radius Health.

R Rizzoli has received consulting fees or advisory board fees from Radius Health, Labatec, Danone, Nestlé, CNIEL and Sandoz.

K Saag reports grant support from Amgen and Radius and consulting fees from Amgen, Radius and Roche. 


\section{Appendix}

Table 5 Intervention thresholds as set by FRAX-based 10-year probability (\%) of a major osteoporotic fracture equivalent to women with a previous fracture (no other clinical risk factors, a body mass index of $24 \mathrm{~kg} / \mathrm{m}^{2}$ and without BMD). The lower assessment thresholds set by FRAX is based on the 10 -year probability (\%) of a major osteoporotic fracture equivalent to women without clinical risk factors (a body mass index of $24 \mathrm{~kg} / \mathrm{m}^{2}$ and without BMD). The upper assessment threshold is set at 1.2 times the intervention threshold. The UK FRAX model is used. From [1], with kind permission from Springer Science and Business Media.

Ten-year fracture probability (\%)

\begin{tabular}{lllll} 
Age range (years) & Intervention threshold* & Lower assessment threshold & Upper assessment threshold** & Lifetime risk at intervention threshold* \\
\hline $50-54$ & 7.8 & 4.0 & 9.4 & 57 \\
$55-59$ & 11 & 5.3 & 13.2 & 54 \\
$60-64$ & 14 & 7.3 & 16.8 & 50 \\
$65-69$ & 19 & 9.8 & 22.8 & 47 \\
$70-74$ & 22 & 12 & 26.4 & 43 \\
$75-79$ & 26 & 16 & 31.2 & 39 \\
$80-84$ & 31 & 20 & 37.2 & 34 \\
$85-89$ & 33 & 18 & 39.6 & \\
\hline
\end{tabular}

*Threshold for high risk

**Threshold for very high risk

Table 6 Pharmaceutical interventions used in the management of postmenopausal osteoporosis. The list is not comprehensive but includes agents approved in Europe, the USA and member countries represented by the authors

\begin{tabular}{ll}
\hline Inhibitors of bone resorption & Stimulators of bone formation \\
\hline Vitamin D derivatives & \\
Alfacalcidol & Abaloparatide \\
Calcidiol & Teriparatide (including biosimilars) \\
Calcitriol & Romosozumab \\
Bisphosphonates & \\
Alendronate (including effervescent formulation) & \\
Clodronate & Uncertain action \\
Neridronate & Strontium ranelate \\
Risedronate (including gastric resistant formulation) & \\
Ibandronate & \\
Zoledronate & \\
MHT and SERMs & \\
Oestrogen only MHT & \\
Opposed MHT (with progestogen) & \\
Tibolone & \\
Bazedoxifene & \\
Raloxifene & \\
Other & \\
Vitamin K & \\
Calcitonin & \\
Denosumab & \\
\hline
\end{tabular}

MHT, menopause hormonal treatment; SERMs, selective oestrogen receptor modulator 
Table 7 Number of postmenopausal women by age in a simulation cohort of 50,633 women from the UK [51] and the proportion (\%) characterised at low, high and very high risk. The high risk category includes women with a prior fracture not characterised at very high risk

\begin{tabular}{|c|c|c|c|c|c|c|c|c|c|}
\hline & \multicolumn{8}{|c|}{ Age (years) } & \multirow[b]{2}{*}{ Total } \\
\hline & $50-54$ & $55-59$ & $60-64$ & $65-69$ & $70-74$ & $75-79$ & $80-84$ & $85+$ & \\
\hline Number & 8799 & 8384 & 8552 & 6671 & 5792 & 4784 & 3807 & 3844 & 50,633 \\
\hline Low risk $(\%)$ & 73.0 & 70.1 & 67.1 & 65.1 & 61.4 & 58.0 & 54.8 & 52.0 & 64.8 \\
\hline High risk (\%) & 13.4 & 15.9 & 17.0 & 19.1 & 22.2 & 24.7 & 28.2 & 31.1 & 19.7 \\
\hline Very high risk (\%) & 13.7 & 14.0 & 16.0 & 16.0 & 16.3 & 17.3 & 17.1 & 16.9 & 15.6 \\
\hline
\end{tabular}

Open Access This article is licensed under a Creative Commons Attribution-NonCommercial 4.0 International License, which permits any non-commercial use, sharing, adaptation, distribution and reproduction in any medium or format, as long as you give appropriate credit to the original author(s) and the source, provide a link to the Creative Commons licence, and indicate if changes were made. The images or other third party material in this article are included in the article's Creative Commons licence, unless indicated otherwise in a credit line to the material. If material is not included in the article's Creative Commons licence and your intended use is not permitted by statutory regulation or exceeds the permitted use, you will need to obtain permission directly from the copyright holder. To view a copy of this licence, visit http://creativecommons.org/licenses/by-nc/4.0/.

\section{References}

1. Kanis JA, Cooper C, Rizzoli R, Reginster J-Y, Scientific Advisory Board of the European Society for Clinical and Economic Aspects of Osteoporosis (ESCEO) and the Committees of Scientific Advisors and National Societies of the International Osteoporosis Foundation (IOF) (2019) European guidance for the diagnosis and management of osteoporosis in postmenopausal women. Osteoporos Int 30:3-44

2. Kanis JA, Cooper C, Rizzoli R, Reginster J-Y (2019) Executive summary of European guidance for the diagnosis and management of osteoporosis in postmenopausal women. Aging Clin Exp Res 31: $15-17$

3. Kanis JA, Cooper C, Rizzoli R, Reginster J-Y (2019) Executive summary of the European guidance for the diagnosis and management of osteoporosis in postmenopausal women. Calcif Tissue Int 104:235-238

4. Johnell O, Oden A, Caulin F, Kanis JA (2001) Acute and long-term increase in fracture risk after hospitalization for vertebral fracture. Osteoporos Int 12:207-214

5. Johnell O, Kanis JA, Oden A, Sernbo I, Redlund-Johnell I, Pettersen C, De Laet C, Jonsson B (2004) Fracture risk following an osteoporotic fracture. Osteoporos Int 15:175-179

6. Nymark T, Lauritsen JM, Ovesen O, Röck ND, Jeune B (2006) Short time-frame from first to second hip fracture in the Funen County Hip Fracture Study. Osteoporos Int 17:1353-1357

7. Giangregorio LM, Leslie WD (2010) Manitoba bone density program. Time since prior fracture is a risk modifier for 10-year osteoporotic fractures. J Bone Miner Res 25:1400-1405

8. van Geel TACM, van Helden S, Geusens PP, Winkens B, Dinant G$\mathrm{J}$ (2009) Clinical subsequent fractures cluster in time after first fractures. Ann Rheum Dis 68:99-102
9. Johansson H, Siggeirsdóttir K, Harvey NC, Odén A, Gudnason V, McCloskey E, Sigurdsson G, Kanis JA (2017) Imminent risk of fracture after fracture. Osteoporos Int 28:775-780

10. Kendler DL, Marin F, Zerbini CAF, Russo LA, Greenspan SL, Zikan V, Bagur A, Malouf-Sierra J, Lakatos P, FahrleitnerPammer A, Lespessailles E, Minisola S, Body JJ, Geusens P, Möricke R, López-Romero P (2018) Effects of teriparatide and risedronate on new fractures in post-menopausal women with severe osteoporosis (VERO): a multicentre, double-blind, doubledummy, randomised controlled trial. Lancet 391(10117):230-240

11. Saag KG, Petersen J, Brandi ML, Karaplis AC, Lorentzon M, Thomas T, Maddox J, Fan M, Meisner PD, Grauer A (2017) Romosozumab or alendronate for fracture prevention in women with osteoporosis. N Engl J Med 377:1417-1427

12. Barrionuevo P, Kapoor E, Asi N, Alahdab F, Mohammed K, Benkhadra K, Almasri J, Farah W, Sarigianni M, Muthusamy K, Al Nofal A, Haydour Q, Wang Z, Murad MH (2019) Efficacy of pharmacological therapies for the prevention of fractures in postmenopausal women: a network meta-analysis. J Clin Endocrinol Metab 104:1623-1630

13. Lou S, Lv H, Yin P, Li Z, Tang P, Wang Y (2019) Combination therapy with parathyroid hormone analogs and antiresorptive agents for osteoporosis: a systematic review and meta-analysis of randomized controlled trials. Osteoporos Int 30:59-70

14. Díez-Pérez A, Marin F, Eriksen EF, Kendler DL, Krege JH, Delgado-Rodríguez M (2019) Effects of teriparatide on hip and upper limb fractures in patients with osteoporosis: a systematic review and meta-analysis. Bone 120:1-8. https://oi.org/10.1016/ j.bone.2018.09.020

15. Russow G, Jahn D, Appelt J, Märdian S, Tsitsilonis S, Keller J (2018) Anabolic therapies in osteoporosis and bone regeneration. Int J Mol Sci 26:20(1)

16. Khosla S, Hofbauer LC (2017) Osteoporosis treatment: recent developments and ongoing challenges. Lancet Diabetes Endocrinol 5: 898-907

17. Kanis JA on behalf of the World Health Organization Scientific Group (2008) Assessment of osteoporosis at the primary healthcare level. Technical Report. WHO Collaborating Centre, University of Sheffield, UK. Available at: https://www.sheffield. ac.uk/FRAX/pdfs/WHO_Technical_Report.pdf Accessed 2 April 2019

18. Kanis JA, Oden A, Johnell O, Johansson H, De Laet C, Brown J, Burckhardt P, Cooper C, Christiansen C, Cummings S, Eisman JA, Fujiwara S, Gluer C, Goltzman D, Hans D, Krieg MA, La Croix A, McCloskey E, Mellstrom D, Melton LJ 3rd, Pols H, Reeve J, Sanders K, Schott AM, Silman A, Torgerson D, van Staa T, Watts NB, Yoshimura N (2007) The use of clinical risk factors enhances the performance of BMD in the prediction of hip and osteoporotic fractures in men and women. Osteoporos Int 18:1033-1046

19. Kanis JA, Harvey NC, Cooper C, Johansson H, Odén A, McCloskey EV, the Advisory Board of the National Osteoporosis 
Guideline Group (2016) A systematic review of intervention thresholds based on FRAX. A report prepared for the National Osteoporosis Guideline Group and the International Osteoporosis Foundation. Arch Osteoporos 11:25

20. Clark P, Denova-Gutiérrez E, Zerbini C, Sanchez A, Messina O, Jaller JJ, Campusano C, Orces CH, Riera G, Johansson H, Kanis JA (2018) FRAX-based intervention and assessment thresholds in seven Latin American countries. Osteoporos Int 29:707-715

21. Kanis JA, EV MC, Johansson H, Strom O, Borgstrom F, Oden A, the National Osteoporosis Guideline Group (2008) Case finding for the management of osteoporosis with FRAX ${ }^{\circledR}$ - assessment and intervention thresholds for the UK. Osteoporos Int 19:1395-1408

22. Tosteson AN, Melton LJ 3rd, Dawson-Hughes B et al (2008) Costeffective osteoporosis treatment thresholds: the United States perspective. Osteoporos Int 19:437-447

23. Kanis JA, Stevenson M, McCloskey EV, Davis S, Lloyd-Jones M (2007) Glucocorticoid-induced osteoporosis: a systematic review and cost-utility analysis. Health Technol Assess; 11: iii-iv, ix-xi, $1-231$

24. Shepstone L, Lenaghan E, Cooper C, Clarke S, Fong-Soe-Khioe R, Fordham R, Gittoes NJ, Harvey I, Harvey N, Heawood A, Holland R, Howe A, Kanis J, Marshall T, O'Neill T, Peters T, Redmond N, Torgerson D, Turner D, McCloskey E (2018) Screening in the community to reduce fractures in older women (SCOOP): a randomised controlled trial. Lancet 391(10122):741-747

25. Kanis JA, Johansson H, Oden A, McCloskey EV (2011) Guidance for the adjustment of FRAX according to the dose of glucocorticoids. Osteoporos Int 22:809-816

26. Leslie WD, Lix LM, Johansson H, Odén A, McCloskey E, Kanis JA (2011) Spine-hip discordance and fracture risk assessment: a physician-friendly FRAX enhancement. Osteoporos Int 22:839-847

27. Johansson H, Kanis JA, Odén A, Leslie WD, Fujiwara S, Glüer CC, Kroger H, LaCroix AZ, Lau E, Melton LJ 3rd, Eisman JA, O'Neill TW, Goltzman D, Reid DM, McCloskey E (2014) Impact of femoral neck and lumbar spine BMD discordances on FRAX probabilities in women: a meta-analysis of international cohorts. Calcif Tissue Int 95:428-435

28. McCloskey EV, Odén A, Harvey NC, Leslie WD, Hans D, Johansson H, Barkmann R, Boutroy S, Brown J, Chapurlat R, Elders PJM, Fujita Y, Glüer CC, Goltzman D, Iki M, Karlsson M, Kindmark A, Kurumatani N, Kwok T, Leung J, Lippuner K, Ljunggren Ö, Lorentzon M, Mellström D, Merlijn T, Oei L, Ohlsson C, Pasco J, Rivadeneira F, Rosengren B, Sornay-Rendu E, Szulc P, Tamaki J, Kanis JA (2016) A meta-analysis of trabecular bone score in fracture risk prediction and its dependence on FRAX. J Bone Miner Res 31:940-948

29. Leslie WD, Johansson H, Kanis JA, Lamy O, Odén A, McCloskey EV, Hans D (2014) Lumbar spine texture enhances 10-year fracture probability assessment. Osteoporos Int 25:2271-2277

30. Leslie WD, Shevroja E, Johansson H, McCloskey EV, Harvey NC, Kanis JA, Hans D (2018) Risk-equivalent T-score adjustment using lumbar spine trabecular bone score (TBS): the Manitoba BMD Registry. Osteoporos Int 29:751-758

31. Leslie WD, Lix LM, Morin SN, Johansson H, Odén A, McCloskey EV, Kanis JA (2015) Adjusting hip fracture probability in men and women using hip axis length: the Manitoba Bone Density Database. J Clin Densitom 19:326-331

32. Masud T, Binkley N, Boonen S, Hannan MT, on behalf of the FRAX Position Conference members (2011) Can falls and frailty be used in FRAX? J Clin Densitom 14:194-204

33. Johansson H, Odén A, Lorentzon M, McCloskey E, Kanis JA, Harvey NC, Karlsson MK, Mellstrom D (2015) Is the Swedish FRAX model appropriate for immigrants to Sweden? Osteoporos Int 26:2617-2622
34. Leslie WD, Rubin MR, Schwartz AZ, Kanis JA (2012) Perspective: diabetes and bone. J Bone Miner Res 27:2231-2237

35. Leslie WD, Johansson H, McCloskey EV, Harvey NC, Kanis JA, Hans D (2018) Comparison of methods for improving fracture risk assessment in diabetes: the Manitoba BMD Registry. J Bone Miner Res 33:1923-1930

36. Whitlock RH, Leslie WD, Shaw J, Rigatto C, Thorlacius L, Komenda P, Collister D, Kanis JA, Tangri N (2019) The Fracture Risk Assessment Tool (FRAX®) predicts fracture risk in patients with chronic kidney disease. Kidney Int 95:447-454

37. Kanis JA, Johansson H, Harvey NC, Lorentzon M, Liu E, Borgström F, McCloskey EV (2019) Correspondence in response to OSIN-D-18-00831 quantifying imminent risk. Osteoporos Int 30:525-526

38. National Institute for Health and Care Excellence (NICE) (2017) Bisphosphonates for treating osteoporosis. Technology appraisal guidance 464. National Institute for Health and Care Excellence, London

39. Compston J, Cooper A, Cooper C, Gittoes N, Gregson C, Harvey N, Hope S, Kanis JA, McCloskey EV, KES P, Reid DM, Selby P, Thompson F, Thurston A, Vine N, The National Osteoporosis Guideline Group (NOGG) (2017) UK clinical guideline for the prevention and treatment of osteoporosis. Arch Osteoporos 12:43

40. Kanis JA, Rizzoli R, Cooper C, Reginster J-Y (2014) Challenges for the development of bone forming agents in Europe. Calcif Tissue Int 94:469-473

41. Beck BR, Daly RM, Singh MA, Taaffe DR (2017) Exercise and Sports Science Australia (ESSA) position statement on exercise prescription for the prevention and management of osteoporosis. $\mathrm{J}$ Sci Med Sport 20:438-445

42. Giangregorio L, El-Kotob R (2017) Exercise, muscle, and the applied load-bone strength balance. Osteoporos Int 28:21-33

43. Bian S, Hu J, Zhang K, Wang Y, Yu M, Ma J (2018) Dairy product consumption and risk of hip fracture: a systematic review and metaanalysis. BMC Public Health 18:165. https://doi.org/10.1186/ s12889-018-5041-5

44. Jensen AL, Lomborg K, Wind G, Langdahl BL (2014) Effectiveness and characteristics of multifaceted osteoporosis group education - a systematic review. Osteoporos Int 25:1209-1224

45. Morfeld JC, Vennedey V, Müller D, Pieper D, Stock S (2017) Patient education in osteoporosis prevention: a systematic review focusing on methodological quality of randomised controlled trials. Osteoporos Int 28:1779-1803

46. Zhou X, Deng H, Shen X, Lei Q (2018) Effect of balance training on falls in patients with osteoporosis: a systematic review and metaanalysis. J Rehabil Med 50:577-581

47. de Souto BP, Rolland Y, Vellas B (2018 Dec 28) Maltais M (2019) Association of long-term exercise training with risk of falls, fractures, hospitalizations, and mortality in older adults: a systematic review and meta-analysis. JAMA Intern Med. https://doi.org/10. 1001/jamainternmed.2018.5406

48. Kemmler W, von Stengel S, Kohl M (2017) Exercise frequency and fracture risk in older adults -how often is enough? Curr Osteoporos Rep 15:564-570

49. Sherrington C, Michaleff ZA, Fairhall N, Paul SS, Tiedemann A, Whitney J, Cumming RG, Herbert RD, Close JCT, Lord SR (2017) Exercise to prevent falls in older adults: an updated systematic review and meta-analysis. Br J Sports Med 51:1750-1758

50. Tricco AC, Thomas SM, Veroniki AA, Hamid JS, Cogo E, Strifler L, Khan PA, Robson R, Sibley KM, MacDonald H, Riva JJ, Thavorn K, Wilson C, Holroyd-Leduc J, Kerr GD, Feldman F, Majumdar SR, Jaglal SB, Hui W, Straus SE (2017) Comparisons of interventions for preventing falls in older adults: a systematic review and meta-analysis. JAMA 318:1687-1699

51. McCloskey E, Kanis JA, Johansson H, Harvey N, Odén A, Cooper A, Cooper C, Francis R, Reid D, Selby P, Davies C, Bowring C, 
Compston J (2015) FRAX-based assessment and intervention thresholds-an exploration of thresholds in women aged 50 years and older in the UK. Osteoporos Int 26:2091-2099

52. Lekamwasam S, Adachi JD, Agnusdei D, Bilezikian J, Boonen S, Borgström F, Cooper C, Diez Perez A, Eastell R, Hofbauer L, Kanis JA, Langdahl BL, Lesnyak O, Lorenc R, McCloskey E, Messina OD, Napoli N, Obermayer-Pietsch B, Ralston SH, Sambrook PN, Silverman S, Sosa M, Stepan J, Suppan G, Wahl DA, Compston JE, for the Joint IOF-ECTS GIO Guidelines Working Group (2012) A framework for the development of guidelines for the management of glucocorticoid-induced osteoporosis. Osteoporos Int 23:2257-2276

53. Dretakis KE, Dretakis EK, Papakitsou EF, Psarakis S, Steriopoulos K (1998) Possible predisposing factors for the second hip fracture. Calcif Tissue Int 62:366-369

54. Lindsay R, Silverman SL, Cooper C, Hanley DA, Barton I, Broy SB, Licata A, Benhamou L, Geusens P, Flowers K, Stracke H, Seeman E (2001) Risk of new vertebral fracture in the year following a fracture. JAMA 285:320-323

55. Ryg J, Rejnmark L, Overgaard S, Brixen K, Vestergaard P (2009) Hip fracture patients at risk of second hip fracture: a nationwide population-based cohort study of 169,145 cases during 1977-2001. J Bone Miner Res 24:1299-1307

56. Banefelt J, Åkesson KE, Spångéus A, Ljunggren O, Karlsson L, Ström O, Ortsäter G, Libanati C, Toth E (2019) Risk of imminent fracture following a previous fracture in a Swedish database study. Osteoporos Int 30:601-609

57. Balasubramanian A, Zhang J, Chen L, Wenkert D, Daigle SG, Grauer A, Curtis JR (2019) Risk of subsequent fracture after prior fracture among older women. Osteoporos Int 30:79-92

58. Kanis JA, Johansson H, Odén A, Harvey NC, Gudnason V, Sanders K, Sigurdsson G, Siggeirsdottir K, Borgström F, McCloskey EV
(2018) Characteristics of recurrent fractures. Osteoporos Int 29: $1747-1757$

59. Johansson H, Siggeirsdottir K, Harvey NC, McCloskey EV, Gudnason V, Sigurdsson G, Lorentzon M, Liu E, Kanis JA (2019) Adjusting FRAX for imminent risk. Osteoporos Int, abstract in press.

60. Cosman F, Nieves JW, Dempster DW (2017) Treatment sequence matters: anabolic and antiresorptive therapy for osteoporosis. J Bone Miner Res 32(198-202):270

61. Kanis JA, Cooper C, Rizzoli R, Abrahamsen B, Al-Daghri NM, Brandi ML, Cannata-Andia J, Cortet B, Dimai HP, Ferrari S, Hadji P, Harvey NC, Kraenzlin M, Kurth A, McCloskey E, Minisola S, Thomas T, Reginster JY (2017) Identification and management of patients at increased risk of osteoporotic fracture: outcomes of an ESCEO expert consensus meeting. Osteoporos Int 28:2023-2034

62. Kanis JA, Cooper C, Rizzoli R, Reginster J-Y (2018) Review of the guideline of the American College of Physicians on the treatment of osteoporosis. Osteoporos Int 29:1505-1510

63. Leder BZ, Tsai JN, Neer RM, Uihlein AV, Wallace PM, BurnettBowie SA (2016) Response to therapy with teriparatide, denosumab, or both in postmenopausal women in the DATA (denosumab and teriparatide administration) study randomized controlled trial. J Clin Densitom 19:346-351

64. Bone HG, Cosman F, Miller PD, Williams GC, Hattersley G, Hu MY, Fitzpatrick LA, Mitlak B, Papapoulos S, Rizzoli R, Dore RK, Bilezikian JP, Saag KG (2018) ACTIVExtend: 24 months of alendronate after 18 months of abaloparatide or placebo for postmenopausal osteoporosis. J Clin Endocrinol Metab 103:2949-2957

Publisher's note Springer Nature remains neutral with regard to jurisdictional claims in published maps and institutional affiliations.

\section{Affiliations}

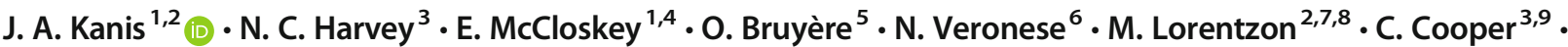

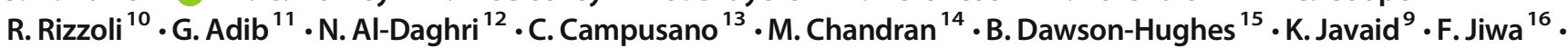

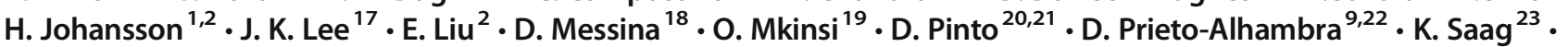 W. Xia ${ }^{24} \cdot$ L. Zakraoui ${ }^{25} \cdot$ J. - Y. Reginster ${ }^{12,26}$}

1 Centre for Metabolic Bone Diseases, University of Sheffield Medical School, Beech Hill Road, S10 2RX Sheffield, UK

2 Mary McKillop Health Institute, Australian Catholic University, Melbourne, Australia

3 MRC Lifecourse Epidemiology Unit, University of Southampton, Southampton, UK

$4 \quad$ MRC and Arthritis Research UK Centre for Integrated Research in Musculoskeletal Ageing Mellanby, Sheffield, UK

5 World Health Organization Collaborating Center for the Public Health Aspects of Musculoskeletal Health and Aging, Department of Public Health, Epidemiology and Health Economics, University of Liège, Liège, Belgium

6 National Research Council, Neuroscience Institute, Aging Branch, Via Giustiniani, 2, 35128 Padova, Italy

7 Geriatric Medicine, Department of Internal Medicine and Clinical Nutrition, Institute of Medicine and Clinical Nutrition, Sahlgrenska Academy, University of Gothenburg, Gothenburg, Sweden
8 Region Västra Götaland, Geriatric Medicine Clinic, Sahlgrenska University Hospital, Gothenburg, Sweden

9 NIHR Musculoskeletal Biomedical Research Unit, University of Oxford, Oxford, UK

10 Service of Bone Diseases, Geneva University Hospitals and Faculty of Medicine, Geneva, Switzerland

11 Syrian National Osteoporosis Society, Damascus, Syria

12 Chair for Biomarkers of Chronic Diseases, Biochemistry Dept., College of Science, King Saud University, Riyadh, Kingdom of Saudi Arabia

13 Clinica Universidad de los Andes and Faculty of Medicine, Universidad de los Andes, Santiago, Chile

14 Osteoporosis and Bone Metabolism Unit, Department of Endocrinology, Singapore General Hospital, ACADEMIA, 20, College Road, Singapore 169856, Singapore 
15 Jean Mayer USDA Human Nutrition Research Center on Aging at Tufts University, Boston, MA, USA

16 Chair of the Committee of Patients Societies at the International Osteoporosis Foundation, Osteoporosis Canada, Toronto, Canada

17 Beacon International Specialist Centre, Petaling Jaya, Malaysia

18 IRO Medical Research Center, Buenos Aires and Rheumatology section, Cosme Argerich, Buenos Aires, Argentina

19 Department of Rheumatology, Ibn Rochd University Hospital, Casablanca, Morocco

20 Department of Physical Therapy, Marquette University, Milwaukee, WI, USA

21 Department of Medical Social Sciences, Feinberg School of Medicine, Northwestern University, Chicago, IL, USA
22

GREMPAL Research Group, CIBERFes and Idiap Jordi Gol, Instituto de Salud Carlos III and Universitat Autonoma de Barcelona, Barcelona, Spain

23 University of Alabama at Birmingham, Birmingham, AL, USA

24 Department of Endocrinology, Key Laboratory of Endocrinology, Ministry of Health, Peking Union Medical College Hospital, Chinese Academy of Medical Sciences \& Peking Union Medical College, Shuaifuyuan No. 1, Wangfujing, Dongcheng District, Beijing 100730, China

25 Service de Rhumatologie, University Tunis Manar and Hôpital Mongi-Slim, la Marsa, Tunisia

26 Department of Public Health, Epidemiology and Health Economics, University of Liège, Liège, Belgium 